\title{
Familial nephropathy in Bracchi Italiani: 8 cases (2012-2019)
}

\author{
Amanda L. Inman DVM \\ Ashley E. Allen-Durrance DVM \\ Rachel E. Cianciolo VMD, PhD
}

Autumn N. Harris DVM

From the Department of Small Animal Clinical Sciences, College of Veterinary Medicine (Inman, Allen-Durrance, Harris), and Division of Nephrology, Hypertension, and Renal Transplantation, College of Medicine (Harris), University of Florida, Gainesville, FL 32610; and Department of Veterinary Biosciences, College of Veterinary Medicine, The Ohio State University, Columbus, OH 43210 (Cianciolo).

Address correspondence to Dr. Allen-Durrance (aeallen@ ufl.edu).

\begin{abstract}
OBJECTIVE
To characterize the signalment, clinical signs, clinical pathological and histologic findings, and outcome in 8 related Bracchi Italiani with proteinuric kidney disease.
\end{abstract}

\section{ANIMALS}

8 client-owned Bracchi Italiani.

\section{PROCEDURES}

Health records submitted to the Bracco Italiano Health Foundation and the Bracco Italiano Club of America between 2012 and 2019 were reviewed for dogs with evidence of nephropathy for which histologic diagnoses were obtained. Pedigree, signalment, clinical signs, diagnostic test results (including microscopic examination of kidney tissue samples collected ante- or postmortem), and outcome were acquired. Results were presented as descriptive statistics.

\section{RESULTS}

The most common clinical sign in affected dogs was inappetence. All dogs were proteinuric, and 4 dogs were azotemic. Seven dogs developed clinical signs of kidney disease and were euthanized a median of 75 days postdiagnosis. Six dogs had glomerular amyloidosis, and I dog each had nephrosclerosis and nonamyloidotic fibrillar glomerulopathy.

\section{CONCLUSIONS AND CLINICAL RELEVANCE}

Results indicated that the clinical presentation may vary in affected dogs, and proteinuria in young or middle-aged Bracchi Italiani should raise the concern for hereditary nephropathy. Prognosis is likely poor once clinical signs are noted.
A myloidosis is characterized by the deposition of insoluble, fibrillary, $\beta$-sheet protein aggregates in the extracellular and intracellular spaces of tissues. ${ }^{1,2}$ The condition is diverse and can be localized or systemic. Although the most common site of amyloid deposition in dogs is in the kidney, any organ or tissue can be affected ${ }^{1,2}$; amyloid deposition is described in the CNS, lungs, skin, and eyes of people. ${ }^{2}$ In dogs, 3 amyloid proteins have been characterized. ${ }^{2}$ Each type of amyloid fibril develops from distinctive precursors secondary to changes in protein folding; however, the histochemical and ultrastructural morphology of all amyloid fibrils is similar. ${ }^{3}$ Often called reactive amyloidosis, AA amyloidosis is the most common type and may be idiopathic or associated with chronic inflammation. ${ }^{2}$

Familial proteinuric kidney disease is reported in many dog breeds. ${ }^{4}$ The underlying genetic mutations are often unknown, but defects in the production or assembly of collagen IV (Alport syndrome) have been identified in several breeds, including Bull Terrier, Dalmatian, English Cocker Spaniel, and Samoyed. ${ }^{4}$ Light microscopy alone may not be sufficient to aid in the diagnosis of the type of proteinuric kidney disease, and renal ultrastructural evaluation may be required. ${ }^{4}$ Juvenile nephropathies, kidney disease with an onset at $<3$ years of age, have been described in dogs such as Dogue de Bordeaux, Rottweiler, and Gordon Setter, among others. ${ }^{4}$ Hereditary focal segmental glomerulosclerosis, which can occur concurrently with a protein-losing enteropathy, has been described in Soft Coated Wheaten Terriers. ${ }^{4}$ Hereditary renal amyloidosis has been described in Chinese
Shar-Pei, Beagles, English Foxhounds, and Abyssinians.,5 Genetic causes of protein-losing nephropathy generally affect young to middle-aged dogs, but variable gene expression or incomplete penetrance modes of inheritance may contribute to a later onset of disease. ${ }^{4,6}$ Amyloidosis in Chinese Shar-Pei occurs secondary to immune dysregulation and a subsequent autoinflammatory disorder. ${ }^{7}$ Genetic analysis of this breed identified 1 primary risk locus; however, a modifier locus was suggested..$^{7,8}$

Proteinuric nephropathy and renal amyloidosis affecting Bracchi Italiani have been recognized ( $\mathrm{R}$ Propernick, Bracco Italiano Club of America, email, December 18,2011 ) but was not mentioned in previous reports. ${ }^{4-6}$ Therefore, the objective of the study reported here was to characterize the signalment, clinical signs, clinical pathological and histologic findings, and outcome for 8 related adult purebred Bracchi Italiani with proteinuric kidney disease.

\section{Materials and Methods}

\section{Case selection criteria}

The Bracco Italiano Club of America and the Bracco Italiano Health Foundation granted access to their archived medical records submitted by dog owners between 2012 and 2019. The databases were searched for dogs with evidence of kidney disease for which a histologic diagnosis was obtained and medical records were available. Approval by the University of Florida Institutional Animal Care and Use Committee was not obtained because this study was retrospective, and all dog owners consented for their 
dogs' records to be reviewed for research purposes at the time when data were submitted to these national breed organizations.

\section{Medical records review}

All health reports submitted to the Bracco Italiano Club of America and the Bracco Italiano Health Foundation were reviewed. Data from 29 dogs were available for review. Twelve dogs had azotemia with an inadequate urine specific gravity or proteinuria with an inactive urine sediment; however, 4 dogs were excluded because of the lack of a histologic diagnosis or an incomplete medical record. Data required for each dog were age at time of diagnosis; sex; initial clinical signs; results of $\mathrm{CBC}$, serum biochemical analysis, and urinalysis; patient outcome; and the histologic examination report for kidney tissue harvested anteor postmortem. Reported results of the CBC, serum biochemical analysis, and urinalysis were from the time of euthanasia or the most recent examination unless otherwise stated; results were obtained from several veterinary diagnostic laboratories that used various hematologic and biochemical analyzers. Pedigrees were also available for all dogs. Medical records were available from the time of diagnosis to the time of euthanasia for 7 of 8 dogs. One dog was owned by one of the authors (ALI) and was available for followup 25 months after diagnosis.

\section{Histologic examination}

Archived samples of kidney tissue from dogs 1, 2, 5 , and 7 were available for histologic reexamination. Archived paraffin-embedded kidney tissue was available for dog 4. A dog owner permitted reexamination of the kidney tissue samples by use of light or fluorescence microscopy following application of special stains and through electron microscopy performed by a board-certified veterinary pathologist with expertise in nephropathology; these examinations had not been performed at the time of necropsy.

Samples of kidney tissue were acquired from 3 dogs by ultrasound-guided percutaneous $(n=2)$ or laparoscopic (1) biopsy and from the remaining 5 dogs at necropsy. All samples were evaluated by board-certified veterinary pathologists. Samples from 5 dogs were examined by the same pathologist, whereas samples from the 3 other dogs were examined by various veterinary pathologists at various veterinary diagnostic laboratories. Amyloidosis was confirmed with light microscopy by the presence of mesangial expansion and a waxy, fibrillar to amorphous, eosinophilic, extracellular material that stained peach with Congo red stain and exhibited apple green birefringence when examined with polarized light (Figure I). ${ }^{3}$ The amyloid stained pale pink with periodic acid-Schiff stain and pale blue with trichrome stain and had minimal uptake of silver as noted with Jones stain. Amyloidosis was confirmed ultrastructurally by the presence of nonbranching, haphazardly arranged fibrils that were 7 to $12 \mathrm{~nm}$ in diameter. Nonamyloidotic fibrillar dis- ease was confirmed on the basis of the lack of uptake of Congo red stain and the presence of fibrils that were 11 to $18 \mathrm{~nm}$ in diameter. Electron microscopy was performed for 3 dogs. The presence of immunofluorescence for anti-IgG, anti-IgM, anti-IgA, anti-C3, and anti- $\lambda$ light-chain antibodies was determined for 2 dogs that had available fresh tissue samples.

\section{Statistical analysis}

Results were presented as median and range. The outcome of interest was survival time. Seven of 8 dogs that were euthanized because of complications of their kidney disease were included in the survival analysis. One dog remained clinically well and was censored. Because of the small sample size, the significance of the association between independent variables and survival time was not assessed.

\section{Results \\ Dogs}

Eight Bracchi Italiani were enrolled in this study. The study population included 5 male dogs (neutered, $\mathrm{n}=3$; sexually intact, 2) and 3 female dogs (spayed, 2; sexually intact, 1). At the time of diagnosis, the median age was 5 years (range, 2 to 10 years). Of 2 primary color combinations recognized for Bracchi Italiani, 3 dogs were brown and white and 5 were orange and white. The dogs came from 4 distinct breeding lines; however, ancestry was common in 6 generations for all dogs. Four dogs were born outside of the US. The familial relationship among the affected dogs is shown (Figure 2).

Of the 21 dogs with medical data available for review from the national breed organizations that were

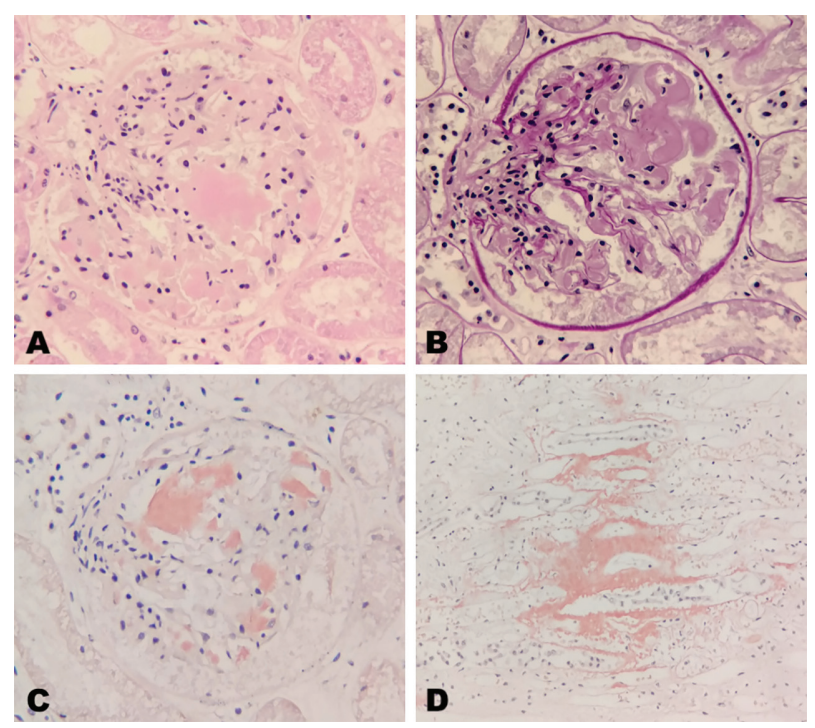

Figure I-Photomicrographs of a glomerulus with amyloid deposition from a kidney tissue sample from a Bracco Italiano ( $\operatorname{dog} 5$ ), with the tissue stained with H\&E stain (A), Periodic acid-Schiff stain (B), or Congo red stain (C and D). Note the amyloid deposition in the papillary interstitium in panel $D$. Magnification $=40 \mathrm{X}$. 
excluded from the study, 18 had common ancestry with the study cohort in 3 generations. Pedigree information was not available for $1 \mathrm{dog}$. These $21 \mathrm{dogs}$ came from 9 breeding lines originating in 5 countries (US, Italy, Netherlands, Finland, and Ireland). Six dogs were born outside of the US.

\section{Clinical signs}

Initial clinical signs were variable, with inappetence (3/8) as the most common clinical sign. Polyuria and polydipsia, weight loss, weakness, cough, and non-weight-bearing lameness were reported for 1 dog each. Two dogs (dogs 2 and 8) were clinically well at time of diagnosis. Dog 1, a 2-year-old sexually intact male, was presented with non-weight-bearing lameness of all limbs and was diagnosed with nonseptic suppurative synovitis and polyarthropathy. Dog 5, a 6-year-old neutered male, was presented with an acute cough. Its condition declined over the next 48 hours, and it became oxygen dependent. At necropsy,

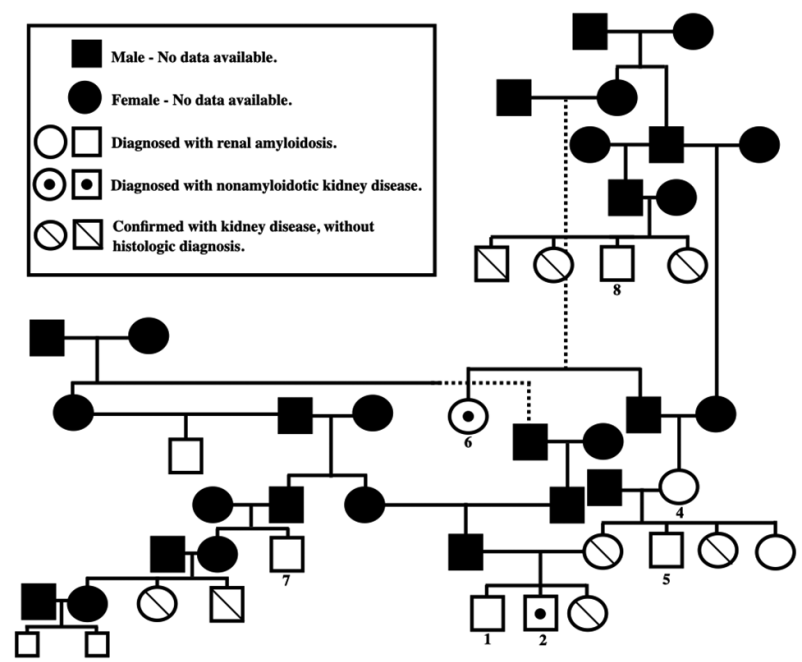

Figure 2-Pedigree chart that shows the familial relationships among the 8 Bracchi Italiani with renal amyloidosis included in the present study. The number (I through 8 ) below the symbol indicates that the dog was included in the present study and is referred to in the article text. it was diagnosed with severe pulmonary thromboemboli and cor pulmonale.

\section{Diagnostic test results}

All dogs were proteinuric, but urine protein-tocreatinine ratios were available for only 5 dogs; the median was 8.3 (range, 1.3 to 30 ; reference interval, $<0.5)$. $^{\text {The remaining } 3 \text { dogs had qualitative pro- }}$ teinuria on the basis of urine dipstick (range, $2+$ to $3+$; reference result, none). ${ }^{6}$ Urinalyses for all dogs revealed an inactive sediment, and aerobic bacterial culture of urine from 5 dogs yielded no bacterial growth. At the time of diagnosis, urine from dog 8 yielded growth of Escherichia coli. After 1 SC injection of $8 \mathrm{mg}$ of cefovecin sodium $/ \mathrm{kg}$, urine sediment was inactive but proteinuria persisted; repeat urine culture was not performed.

Clinical pathological data for each dog are summarized (Table I). Four dogs were azotemic. Serum creatinine concentrations were available for 7 dogs, and the median concentration was $4.1 \mathrm{mg} / \mathrm{dL}$ (range, 0.8 to $7.8 \mathrm{mg} / \mathrm{dL}$; reference interval, 0.6 to $1.4 \mathrm{mg}$ / dL). For the dog for which a serum creatinine concentration was not available, its concentration was reported by the attending veterinarian as within the reference interval. Chronic kidney disease staging on the basis of the criteria of the International Renal Interest Society indicated that 4 dogs had stage 1, 1 dog had stage 3 , and 3 dogs had stage $4 .^{9}$ Median urine specific gravity was 1.016 (range, 1.008 to 1.036 ). All dogs were hypoalbuminemic, with a median serum albumin concentration of $2.4 \mathrm{~g} / \mathrm{dL}$ (range, 1.6 to 2.9 $\mathrm{g} / \mathrm{dL}$; reference interval, 3.2 to $4.1 \mathrm{~g} / \mathrm{dL}$ ). Three dogs had mild mature neutrophilia; median neutrophil count was $7.5 \times 10^{3} / \mu \mathrm{L}$ (range, $4.2 \times 10^{3} / \mu \mathrm{L}$ to $14.8 \times$ $10^{3} / \mu \mathrm{L}$; reference interval, $2.7 \times 10^{3} / \mu \mathrm{L}$ to $9.4 \times 10^{3} /$ $\mu \mathrm{L})$. Anemia was recorded for 5 dogs, with a median Hct of $33 \%$ (range, $13 \%$ to $54 \%$; reference interval, $41 \%$ to $58 \%$ ).

Abdominal ultrasound reports were available for 5 dogs. Four dogs were reported to have had decreased corticomedullary distinction for both kidneys on the basis of the ultrasonographic examinations performed at

Table I-Results of hematologic and serum biochemical analyses for and histologic diagnoses of kidney samples from 8 Bracchi Italiani that came from 4 breeding lines but had common ancestry.

\begin{tabular}{|c|c|c|c|c|c|c|c|c|c|c|}
\hline Dog & $\begin{array}{c}\text { Urine } \\
\text { protein-to } \\
\text {-creatinine } \\
\text { ratio }\end{array}$ & $\begin{array}{c}\text { Creatinine } \\
\text { (mg/dL; RI, } \\
0.6-1.4 \mathrm{mg} / \mathrm{dL})\end{array}$ & $\begin{array}{c}\text { BUN } \\
\text { (mg/dL; RI, } \\
\text { 9-26 mg/dL) }\end{array}$ & $\begin{array}{l}\text { Albumin } \\
\text { (g/dL; RI, } \\
3.2-4.1 \mathrm{~g} / \mathrm{dL} \text { ) }\end{array}$ & $\begin{array}{l}\text { Cholesterol } \\
\text { (mg/dL; } \\
\text { RI, I36-392 } \\
\text { mg/dL) }\end{array}$ & $\begin{array}{l}\text { Phosphorus } \\
\text { (mg/dL; } \\
\text { RI, 2.7-5.4 } \\
\text { mg/dL) }\end{array}$ & $\begin{array}{l}\text { Calcium } \\
\text { (mg/dL; } \\
\text { RI, 9.4-II.I } \\
\text { mg/dL) }\end{array}$ & $\begin{array}{c}\text { Neutrophil } \\
\text { count } \\
\left(\times 10^{3} / \mu \mathrm{L} ;\right. \\
\text { RI, } 2.7 \times 10^{3} / \mu \mathrm{L} \\
\left.\text { to } 9.4 \times 10^{3} / \mu \mathrm{L}\right)\end{array}$ & $\begin{array}{c}\text { Hct } \\
(\% ; 41 \%-58 \%)\end{array}$ & Histologic diagnosis \\
\hline I & 30.3 & 0.9 & 7 & 1.7 & 301 & 4.4 & 8.6 & 14.4 & 23 & Glomerular amyloidosis \\
\hline 2 & 1.3 & 1.3 & 25 & 2.6 & 217 & 3.3 & 9.5 & 5.3 & 45 & $\begin{array}{l}\text { Nonamyloidotic fibrillar } \\
\text { glomerulopathy }\end{array}$ \\
\hline $3^{*}$ & 15.4 & NA & NA & 2.3 & 332 & NA & NA & NA & NA & Glomerular amyloidosis \\
\hline 4 & 2.6 & 7.8 & 121 & 2 & 356 & 7.6 & 10.3 & 7.5 & 13 & Glomerular amyloidosis \\
\hline 5 & $>8.3$ & 0.8 & 14 & 1.6 & 563 & 4.5 & 8.7 & 14.8 & 54 & Glomerular amyloidosis \\
\hline 6 & $\mathrm{NP} \dagger$ & 6.6 & 136 & 2.9 & 279 & 9.6 & 12.5 & 4.2 & 38 & Nephrosclerosis \\
\hline 7 & $N P \ddagger$ & 4.1 & 117 & 2.4 & 237 & 3.9 & 10.8 & 7.1 & 33 & Glomerular amyloidosis \\
\hline 8 & $N P \ddagger$ & 6.3 & 108 & 2.6 & 278 & 5 & 12 & 13.8 & 33 & Glomerular amyloidosis \\
\hline
\end{tabular}

*Results not available (NA) for all analytes but were reported by the attending veterinarian to be within their reference intervals. $\dagger$ Urine protein $2+$ based on urine dipstick result. fUrine protein $3+$ based on urine dipstick result.

$\mathrm{NP}=$ Not performed. $\mathrm{RI}=$ Reference interval. 
Table 2-Histologic findings of kidney tissue samples for the dogs of Table I.

\begin{tabular}{clc} 
Type of lesion & Histologic finding & $\begin{array}{c}\text { No. of } \\
\text { dogs }\end{array}$ \\
\hline $\begin{array}{cl}\text { Primary lesion } \\
\text { Glomerular }\end{array}$ & $\begin{array}{l}\text { Glomerular amyloidosis } \\
\text { Nonamyloidotic fibril deposition } \\
\text { Medullary }\end{array}$ & 6 \\
Mecullary amyloidosis & I \\
Interstitial & & \\
Tubular & Interstitial fibrosis & \\
& Lymphoplasmacytic inflammation & 6 \\
Tubular atrophy & 4 \\
Glomerular & Tubular degeneration & 2 \\
& Soft tissue mineralization & 4 \\
& Periglomerular fibrosis & 3 \\
& Glomerular tuft adhesions & 2 \\
& Thickened bowman capsule & I \\
& Crescent formation & I \\
& Glomerular hypercellularity & I
\end{tabular}

referral facilities by a radiology resident with captured images reviewed by a board-certified veterinary radiologist (dogs 1,2 , and 4 ) or by a veterinarian whose practice was limited to small animal internal medicine (dog 3 ). Moderate bilateral pyelectasia was also reported for dogs 2 and 4, and the kidneys were unremarkable for $\operatorname{dog} 5$ on the basis of an ultrasonographic examination performed at a secondary referral facility.

\section{Histologic evaluation}

Primary and secondary renal histologic findings are summarized (Tables 1 and 2). Six of the 8 dogs were diagnosed with glomerular amyloidosis; renal interstitial amyloid deposition was noted for 2 of the 6 dogs and interstitial nephritis for 4 of the 6 dogs. Kidney tissue samples from 2 dogs (dogs 1 and 4) also underwent electron microscopic examination to confirm glomerular amyloidosis. Extrarenal amyloid deposition in the adrenal gland, duodenum, and jejunum was noted in $1 \operatorname{dog}(\operatorname{dog} 1)$. Histologic evaluation of all tissues was not performed for all dogs.

Secondary histologic changes that were consistent with chronic kidney disease were also reported. The kidney tissue from 6 of 8 dogs exhibited mononuclear interstitial nephritis and fibrosis. Other nonspecific findings included tubular atrophy $(\mathrm{n}=4)$, mineralization of soft tissues (4), and periglomerular fibrosis (3). The presence of immunofluorescence for anti-IgG, anti-IgM, anti-IgA, anti-C3, and anti- $\lambda$ lightchain antibodies was determined for $2 \operatorname{dogs}(\operatorname{dogs} 1$ and 2$)$ and revealed nonspecific immunofluorescence patterns without evidence of immune complex disease.

Dog 2 was diagnosed with nonamyloidotic fibrillar glomerulopathy (Figure 3). Light microscopy revealed nonspecific changes including few fetal glomeruli admixed with a greater number of large hypercellular glomeruli and mild mononuclear periglomerular inflammation. Also, mild mesangial expansion was noted; ultrastructural examination indicated the expansion was due to an accumulation of fibrils that had a mean crosssectional diameter of $14 \mathrm{~nm}$ (range, 11 to $18 \mathrm{~nm}$ ) that did not stain with Congo red stain. These findings were con-

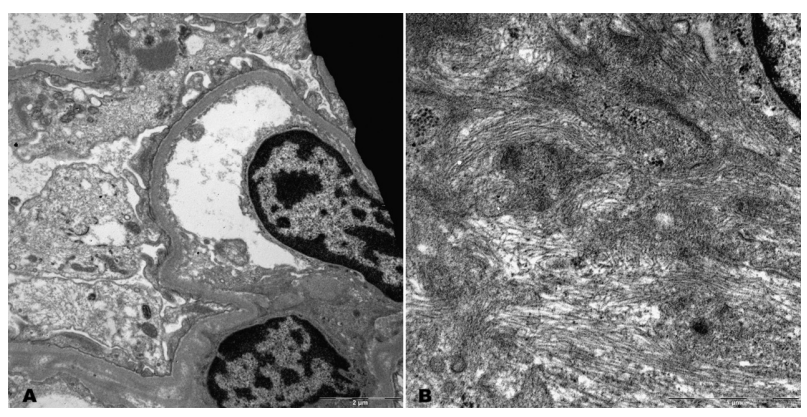

Figure 3-Photomicrographs obtained with an electron microscope of kidney tissue samples from I Bracco Italiano (dog 2) diagnosed with nonamyloidotic fibrillar glomerulopathy. A-Segmental podocyte foot process has effaced a glomerulus. Bar $=2 \mu \mathrm{m}$. BMesangial nonamyloidotic fibril deposition is noted. Bar $=1 \mu \mathrm{m}$.

sistent with nonamyloid fibril deposition. Additionally, subendothelial lucent expansion was noted with new glomerular basement membrane material, a lesion that is seen in hypertensive people. ${ }^{10}$ However, this dog consistently had normal arterial blood pressure measurements.

Dog 6 was diagnosed with severe chronic nephrosclerosis and inflammation. The kidney samples had extensive degenerative changes with fibrosis of the glomeruli and interstitial tissue. A mononuclear interstitial nephritis was also noted. Electron microscopic and immunofluorescent examinations were not performed. This dog also had renal secondary hyperparathyroidism and gastric mineralization diagnosed at the time of necropsy.

\section{Outcome}

The median survival time postdiagnosis was 75 days (range, 10 to $\mathbf{4 7 6}$ days). Seven dogs were euthanized because of perceived poor quality of life (lethargy and inappetence, $\mathrm{n}=5$; respiratory distress, 1 ; progressive azotemia refractory to medical management and anemia, 1). One dog was alive at the time of the last follow-up, 25 months after diagnosis. The 2 dogs with the longest survival times were the maternal granddam (dog 4; 476 days; diagnosis, renal amyloidosis) and grandoffspring (dog 2 [male]; 25 months; diagnosis, nonamyloidotic fibrillary glomerulopathy; Figure 2). Dog 2 was stabilized with medical management that included a prescription of moderately restricted protein diet ( $2 \mathrm{~g}$ of dietary protein/ $\mathrm{kg} / \mathrm{d}$ ), omega-3 fatty acids ( $72 \mathrm{mg}$ of total docosahexaenoic acid and eicosapentaenoic acid $/ \mathrm{kg} / \mathrm{d}$ ), and a probiotic (Profivex; Vetnique Labs LLC). Mild proteinuria did not decrease with enalapril administration $(0.25$ to $0.5 \mathrm{mg}$ / $\mathrm{kg}$, PO, q $12 \mathrm{~h}$ ); however, the urine protein-to-creatinine ratio decreased to 0.4 with the addition of telmisartan (1 $\mathrm{mg} / \mathrm{kg}, \mathrm{PO}, \mathrm{q} 24 \mathrm{~h}$ ).

Dog 4 had isosthenuria and mild azotemia after ingestion of many raisins 3 years prior to its presentation. Whether isosthenuria and azotemia were because of raisin toxicosis or early familial kidney disease was unknown; however, the dog owner reported that the dog had polyuria and polydipsia prior to raisin ingestion. Urinalysis to determine the presence of proteinuria was not done at that time, and the dog was not reexamined until 
3 years later when its health had deteriorated. Its survival time after the second presentation was 476 days. This dog was managed with administration of water $(100 \mathrm{~mL} /$ $\mathrm{kg} / \mathrm{d}$ ) through an esophageal feeding tube, omeprazole (1 mg/kg, PO, q $24 \mathrm{~h})$, famotidine ( $1 \mathrm{mg} / \mathrm{kg}$, PO, q $8 \mathrm{~h})$, enalapril (0.3 mg/kg, PO, q $12 \mathrm{~h})$, amlodipine $(0.2 \mathrm{mg} / \mathrm{kg}$, $\mathrm{PO}, \mathrm{q} 12 \mathrm{~h}$ ), sucralfate ( $37 \mathrm{mg} / \mathrm{kg}, \mathrm{PO}, \mathrm{q} 6 \mathrm{~h})$, ondansetron $(0.3 \mathrm{mg} / \mathrm{kg}, \mathrm{PO}, \mathrm{q} 8 \mathrm{~h})$, omega-3 fatty acids, a prebioticprobiotic (Azodyl; Vetoquinol USA Inc), a fiber supplement (Metamucil; Procter and Gamble), a multivitamin (Total Formula-2; Integrative Therapeutics Inc), and a home-cooked meal plan formulated by a board-certified veterinary nutritionist.

Dog 7 was presented because of inappetence, at which time the dog was markedly azotemic and proteinuric. However, 5 months earlier, it had $3+$ proteinuria (urine dipstick), mild anemia, mild hypoalbuminemia, increased BUN concentration, serum creatinine concentration within its reference interval, and a urine specific gravity of 1.017. No clinical signs attributed to kidney disease were noted at that time, and follow-up examination was not performed.

\section{Discussion}

The objective of the study reported here was to characterize the signalment, clinical signs, clinical pathological and histologic findings, and outcome of 8 related adult purebred Bracchi Italiani with proteinuric kidney disease. This retrospective analysis revealed evidence of familial renal amyloidosis and substantiated the anecdotal reports of familial proteinuric kidney disease in this breed.

Chronic inflammatory conditions often precede reactive amyloidosis, and a hereditary autoinflammatory disease has been suggested in the development of amyloidosis in Chinese Shar-Pei. ${ }^{1,8}$ Abnormal secretion of interleukin- $1 \beta$ in autoinflammatory disease leads to the hepatic induction of serum amyloid $\mathrm{A}^{7}$ This underlying immune dysregulation may play a role in the progression and severity of reactive amyloidosis. ${ }^{7}$ Further research is needed to investigate whether Bracchi Italiani exhibit an autoinflammatory disease similar to Chinese Shar-Pei.

Adult-onset familial renal amyloidosis has been described in Chinese Shar-Pei, Beagles, and English Foxhounds. ${ }^{4}$ The median age in the cohort of Bracchi Italiani in the present study was 5 years, which was younger than the median of 9 years reported in a previous study ${ }^{1}$ that included an evaluation of renal amyloidosis in dogs other than Chinese Shar-Pei. The younger age of the dogs in the present study supports a familial disease, but their wide range of ages ( 2 to 10 years) may indicate variable gene expression in the form of incomplete penetrance, a protective haplotype, or a modifier locus. 6,7

Of the 21 dogs for which medical records were available but that were not included in the present study, 18 shared common ancestry within 3 generations to that of the study cohort; however, the importance of this is unclear. Yet, this finding may indicate that the penetrance of amyloidosis is a problem in the breed, rather than within 1 family of dogs. The close familial relationships of these dogs illustrated the low genetic variability in this breed. ${ }^{11}$
Even dogs that appear to be only distantly related on the basis of pedigree analysis may be genotypically similar, thus limiting the value of simple pedigree analysis.

The presenting complaints for the Bracchi Italiani in the present study were variable and nonspecific. The most common presenting complaint was inappetence, with others that included polyuria and polydipsia, weight loss, weakness, cough, and non-weight-bearing lameness. Although many of these complaints are common in chronic kidney disease, their variability illustrated the importance of a thorough diagnostic investigation in ill Bracchi Italiani. ${ }^{12}$ Clinical deterioration is often rapid once clinical signs are noted. After retrospective analysis, evidence of kidney disease was found in 2 of $8 \mathrm{dogs}$ (dogs 4 and 7) prior to diagnosis by the attending veterinarians, which exemplified the importance of screening diagnostic testing (CBC, serum biochemical analysis, and urinalysis) in healthy Bracchi Italiani and further investigation of any kidney-related abnormalities that are identified, regardless of patient age. Earlier diagnosis may permit earlier disease management and subsequent improved survival times.

All dogs in the present study were proteinuric and hypoalbuminemic, with proteinuria likely due to kidney disease. However, the severity of hypoalbuminemia did not consistently correlate with the severity of proteinuria. Thus, the development of hypoalbuminemia may be multifactorial. In addition to loss of protein in the urine, decreased serum albumin may develop secondary to systemic inflammation because albumin is a negative acutephase protein. Chronic enteropathy or liver dysfunction as causes of hypoalbuminemia was not evident for any dog, but they, especially hepatic amyloidosis, could not be ruled out because liver tissue was not available for histologic evaluation in most situations.

Four dogs were azotemic at the time of diagnosis, with increased serum creatinine concentration likely attributed to the tubulointerstitial disease. However, severe glomerular lesions may have altered postglomerular perfusion and worsened azotemia, and concurrent prerenal azotemia also could not be excluded. Azotemia was inconsistent in dogs with renal amyloidosis, which differs from familial amyloidosis in Chinese Shar-Pei, in which $94 \%$ of dogs were reported $^{1}$ to be azotemic. Azotemia may be more common in Chinese Shar-Pei because medullary amyloid deposition likely always occurs, as was noted in nearly $100 \%$ of dogs in that study, ${ }^{1}$ compared with the Bracchi Italiani in the present study. Only 2 of the 6 Bracchi Italiani with renal amyloidosis had medullary amyloid deposition; however, these dogs did not have azotemia.

Thirty-eight percent of dogs (3/8) had mature neutrophilia, which was less than the percentage of those dogs with a mature neutrophilia (70\%) reported in a previous study. ${ }^{1}$ Neutrophilia may be attributed to an inflammatory or autoinflammatory disease that leads to chronic stimulation of the immune system and production of inflammatory cytokines. These have been postulated as a cause of leukocytosis in Chinese Shar-Pei and people affected with renal amyloidosis., ${ }^{2,7}$

Dog 2 was diagnosed with a nonamyloidotic fibrillar glomerulopathy, a rare cause of kidney disease in animals 
and people.,13 The size and arrangements of the fibrils in the kidneys of this dog may be consistent with fibronectin glomerulopathy or fibrillary glomerulonephritis. ${ }^{13,14}$ The mean diameter of the fibrils in dog 2 was larger than the average diameter seen for amyloid, and Congo rednegative amyloidosis has not been reported in the veterinary literature. An association between amyloidotic and nonamyloidotic fibrillar glomerulopathy has also not been reported in the veterinary literature, and reports of affected people are rare. One case report ${ }^{15}$ is of a man with Familial Mediterranean Fever who developed fibrillary glomerulonephritis without evidence of amyloidosis. The authors of this case report postulated that because of the similarity between the etiology, deposition, and structure of fibrillary glomerulonephritis and amyloidosis, the occurrence of fibrillary glomerulonephritis without amyloidosis was related to Familial Mediterranean Fever and circulating immunogenic molecules. This suggests that a similar link may exist in cases of familial disease. The age ( 2 years old) and family history for $\operatorname{dog} 2$ suggested that this fibrillar glomerulopathy was hereditary and related to the family's amyloidosis and possibly an underlying immunogenic condition.

Dog 6 was diagnosed with nephrosclerosis, and although this dog had a family history of renal amyloidosis, whether it had acquired chronic kidney disease rather than hereditary kidney disease was unclear. Ultrastructural and immunofluorescent examination of the kidney tissue was not performed. Autoinflammatory diseases, such as Familial Mediterranean Fever, have been associated with a spectrum of nonamyloidotic nephropathies. ${ }^{16}$ Tubular function decreases in people with Familial Mediterranean Fever even in the absence of amyloidosis, and acute kidney injury associated with this disease may be primarily tubular. ${ }^{17,18}$ With this dog's family history and rapid clinical progression, familial disease was suspected.

One limitation of the present study was the small number of dogs, which precluded statistical analysis to assess independent variables, such as azotemia or severity of hypoalbuminemia, with survival time. Also, kidney tissue from 5 of 8 dogs was evaluated at 1 veterinary diagnostic laboratory, but histologic interpretations may have varied among pathologists there and among pathologists at various other laboratories. Because the present study was retrospective, tissue samples may not have been similarly evaluated. For example, amyloid deposition in dog 4 was not noted until archived tissue was reevaluated 6 years after the time of necropsy. Kidney tissue from $\operatorname{dog} 6$ was evaluated at a commercial veterinary diagnostic laboratory, and the complete diagnosis may not have been obtained without electron microscopic examination, especially in the case of nonamyloidotic fibrillar disease.

The findings of the present study confirmed familial renal amyloidosis in a cohort of Bracchi Italiani. This condition was most often noted in young to middle-aged dogs. Proteinuria occurred frequently and was often severe, and affected dogs were variably azotemic. The 2 dogs with nonamyloidotic disease may represent the spectrum of nephropathy seen with an underlying autoinflammatory condition. Survival time was poor with a median survival time of 75 days postdiagnosis, which agreed with the previously described ${ }^{1}$ poor prognosis of amyloidosis in dogs. These results may inform further research of familial proteinuric nephropathy and underlying autoinflammatory disease in Bracchi Italiani.

\section{Acknowledgments}

Funded by the Department of Small Animal Clinical Sciences at the University of Florida.

The authors declare that there were no conflicts of interest.

\section{References}

1. Segev G, Cowgill LD, Jessen S, Berkowitz A, Mohr CF, Aroch I. Renal amyloidosis in dogs: a retrospective study of 91 cases with comparison of the disease between Shar-Pei and nonShar-Pei dogs. J Vet Intern Med. 2012;26(2):259-268.

2. Benson MD, Buxbaum JN, Eisenberg DS, et al. Amyloid nomenclature 2018: recommendations by the International Society of Amyloidosis (ISA) nomenclature committee. Amyloid. 2018;25(4):215-219.

3. Sipe JD, Benson MD, Buxbaum JN, et al. Amyloid fibril proteins and amyloidosis: chemical identification and clinical classification International Society of Amyloidosis 2016 nomenclature guidelines. Amyloid. 2016;23(4):209-213.

4. Littman MP. Protein-losing nephropathy in small animals. Vet Clin North Am Small Anim Pract. 2011;41(1):31-62.

5. Bowles MH, Mosier DA. Renal amyloidosis in a family of Beagles. J Am Vet Med Assoc. 1992;201(4):569-574.

6. Harley L, Langston C. Proteinuria in dogs and cats. Can Vet J. 2012;53(6):631-638.

7. Olsson M, Tintle L, Kierczak M, et al. Thorough investigation of a canine autoinflammatory disease (AID) confirms one main risk locus and suggests a modifier locus for amyloidosis. PLOS One. 2013;8(10):e75242. doi:10.1371/journal.pone.0075242

8. Metzger J, Nolte A, Uhde A-K, Hewicker-Trauwein M, Distl $\mathrm{O}$. Whole genome sequencing identifies missense mutation in $M T B P$ in Shar-Pei affected with autoinflammatory disease (SPAID). BMC Genomics. 2017;18(1):348. doi:10.1186/ s12864-017-3737-z

9. Staging of chronic kidney disease. International Renal Interest Society. Accessed August 11, 2019. www.iris-kidney.com/ pdf/IRIS_Staging_of_CKD_modified_2019.pdf

10. Batal I, Domsic RT, Medsger TA, Bastacky S. Scleroderma renal crisis: a pathology perspective. J Rbeumatol. 2010;2010:543704. doi:10.1155/2010/543704

11. Ciampolini R, Cecchi F, Bramante A, Casetti F, Presciuttini S Genetic variability of the Bracco Italiano dog breed based on microsatellite polimorphism. Ital J Anim Sci. 2011;10(4):e59. doi:10.4081/ijas.2011.e59

12. O'Neill DG, Elliott J, Church DB, McGreevy PD, Thomson PC, Brodbelt DC. Chronic kidney disease in dogs in UK veterinary practices: prevalence, risk factors, and survival. $J$ Vet Intern Med. 2013;27(4):814-821.

13. Nasr SH, Valeri AM, Cornell LD, et al. Fibrillary glomerulonephritis: a report of 66 cases from a single institution. Clin J Am Soc Nepbrol. 2011;6(4):775-784.

14. Wu J, Zhou Y, Huang X, Huang L, Tang Z. Fibronectin glomerulopathy: a rare autosomal dominant glomerular disease. Chin Med J (Engl). 2017;130(18):2261-2262.

15. Fisher PW, Ho LT, Goldschmidt R, Semerdian RJ, Rutecki GW. Familial Mediterranean fever, inflammation and nephrotic syndrome: fibrillary glomerulopathy and the M6801 missense mutation. BMC Nephrol. 2003;4:6. doi:10.1186/1471-2369-4-6

16. Said R, Hamzeh Y, Said S, Tarawneh M, al-Khateeb M. Spectrum of renal involvement in familial Mediterranean fever. Kidney Int. 1992;41(2):414-419.

17. Akkuș S, Calişkan S, Kasapçopur O. Tubular functions in familial Mediterranean fever. Turk J Pediatr. 2002;44(4):317-320.

18. Saatci U, Ozdemir S, Ozen S, Bakkaloglu A. Serum concentration and urinary excretion of $\beta_{2}$-microglobulin and microalbuminuria in familial Mediterranean fever. Arch Dis Child. 1994;70(1):27-29. 